Check for updates

Cite this: RSC Adv., 2019, 9, 17065

Received 14th April 2019

Accepted 14th May 2019

DOI: 10.1039/c9ra02817j

rsc.li/rsc-advances

\section{Sauchinone inhibits high glucose-induced oxidative stress and apoptosis in retinal pigment epithelial cells $\uparrow$}

\author{
Yang Shi, Yongzhou Zhang, (D) * Yan Li and Chenjun Tong
}

\begin{abstract}
Diabetic retinopathy (DR) is a common complication of diabetes mellitus and results in acquired blindness among working-age adults. It has been demonstrated that high glucose (HG)-induced oxidative stress and cell apoptosis in retinal pigment epithelial (RPE) cells are major factors for the pathogenesis of DR. Sauchinone, one of the active lignan isolated from Saururus chinensis, was reported to possess anti-oxidant and anti-apoptosis effects. In the present study, we investigated the effects of sauchinone on HG-induced oxidative stress and apoptosis in ARPE19 cells. Our results proved that sauchinone improved the cell viability of HG-induced ARPE-19 cells. Moreover, sauchinone treatment caused a decrease in intracellular reactive oxygen species (ROS) generation and an increase in the activities of superoxide dismutase (SOD), glutathione peroxidase (GPX), and catalase (CAT). Besides, flow cytometry showed that the apoptotic rate in sauchinone-treated ARPE-19 cells obviously decreased as compared in the HG-treated cells. Western blot indicated that sauchinone treatment caused a significant decrease in bax expression and increase in bcl-2 expression in HG-treated ARPE-19 cells. Sauchinone treatment enhanced the HG-caused induction of p-Akt, nuclear factor erythroid 2-related factor (Nrf2), and heme oxygenase-1 (HO-1) expressions in ARPE-19 cells. However, the inhibitor of Akt, LY294002, reversed the effects of sauchinone on cell viability, oxidative stress, and cell apoptosis in HG-treated ARPE-19 cells. These findings suggested that sauchinone treatment prevented HG-induced oxidative stress and apoptosis via regulating the Akt/Nrf2/HO-1 pathway in HG-induced RPE cells. These findings suggested that sauchinone might be a therapeutic agent for the treatment and prevention of DR.
\end{abstract}

\section{Introduction}

Diabetic retinopathy (DR) is one of the common complications in diabetes mellitus and remains a leading cause of acquired blindness among working-age adults. ${ }^{1-3}$ It is well known that diabetes mellitus is an increasingly prevalent and chronic condition characterized by hyperglycemia. ${ }^{2}$ Sustained hyperglycemia is a major factor for oxidative stress and chronic inflammation., ${ }^{4,5}$ Retina is a highly specialized tissue that is normally protected by the inner and outer blood-retinal barriers. $^{6}$ The retinal pigment epithelial (RPE) cells are a group of cells of retinal pigmented epithelium that constitute the outer blood-retinal barrier. In diabetic patients, RPE cells are easily subjected to high glucose (HG)-induced oxidative stress, which finally lead to cell apoptosis. ${ }^{4,6}$ These pathological changes contribute to the rupture of the blood-retinal barrier, which promotes the development of macular edema, the foremost symptom of DR, resulting in sight loss among diabetic

Department of Pharmacy, Huaihe Hospital of Henan University, No. 115 of Ximen Street, Kaifeng 475000, China. E-mail: kfzhangyongzhou@126.com; Tel: +86-0371-23906368

† Electronic supplementary information (ESI) available. See DOI: $10.1039 / \mathrm{c} 9 \mathrm{ra} 02817 \mathrm{j}$ patients. ${ }^{6}$ Herein, attenuating the HG-induced oxidative stress and cell apoptosis in RPE cells may become a new pharmacotherapy for the treatment of DR. ${ }^{4}$

Sauchinone, one of the active lignan isolated from Saururus chinensis, was reported to possess broad bioactivities, such as anti-inflammatory, anti-oxidant, anti-tumor, anti-apoptosis and anti-obesity effects. ${ }^{7-10}$ For example, sauchinone protected against oxidative stress-induced skeletal muscle myoblast damage. ${ }^{11}$ However, the effect of sauchinone on DR is still unclear. In the present study, we investigated the protective effect of sauchinone against HG-induced oxidative stress and apoptosis in RPE cells.

\section{Materials and methods}

\subsection{Cell culture and treatment}

The human RPE cell line ARPE-19 was obtained from the American Type Culture Collection (ATCC, Manassas, VA, USA). Cells were cultured in DMEM-F12 medium (Life Technologies, Grand Island, NY, USA) containing $2.5 \mathrm{mM}$ L-glutamine, 10\% fetal bovine serum (FBS), and $0.1 \%$ streptomycin/penicillin (Sigma-Aldrich, St. Louis, MO, USA). The medium was supplemented with either normal glucose (NG, $5.0 \mathrm{mM}$ ) or HG (25 $\mathrm{mM}$ ). Cells were grown in an atmosphere containing $5 \% \mathrm{CO}_{2}$ at 
$37{ }^{\circ} \mathrm{C}$. When mentioned, cells were cultured in the medium supplemented with either normal glucose (NG, $5.0 \mathrm{mM})$ or $\mathrm{HG}$ (25 mM) for $48 \mathrm{~h}$. Cells in the sauchinone treatment group were pretreated with different dosages of sauchinone $(5,10$, and 20 $\mu \mathrm{M} ; \geq 98 \%$, Sigma-Aldrich) for $2.0 \mathrm{~h}$, followed by incubation in HG (25 mM) condition for $48 \mathrm{~h}$. The chemical structure of sauchinone is shown in ESI Fig. $1 . \dagger$

\subsection{Cell viability assay}

The cell viability of ARPE-19 cells was determined using the 3(4,5-dimethylthiazol-2-yl)-2,5-diphenyltetrazolium bromide (MTT) assay. In brief, ARPE-19 cells $\left(5 \times 10^{3}\right.$ cells per well) were cultured in 96-well plates and incubated with $5 \% \mathrm{CO}_{2}$ at $37{ }^{\circ} \mathrm{C}$. Then, ARPE-19 cells were incubated with a series of concentrations of sauchinone $(0,5,10,20$, and $40 \mu \mathrm{M})$ for $48 \mathrm{~h}$ or pretreated with different dosages of sauchinone $(0,5,10$, and 20 $\mu \mathrm{M})$ for $2 \mathrm{~h}$, followed by incubation in $\mathrm{HG}(25 \mathrm{mM})$ condition for $48 \mathrm{~h}$. Subsequently, the cells were exposed to $0.5 \mathrm{mg} \mathrm{ml}^{-1}$ MTT (Sigma) for $4 \mathrm{~h}$. Then, the formazan was dissolved by adding dimethyl sulfoxide (DMSO). Absorbance was measured at a wavelength of $490 \mathrm{~nm}$ using a microplate photometer (Thermo Fisher Scientific Inc., Waltham, MA, USA).

\subsection{Detection of intracellular reactive oxygen species (ROS)}

The $2^{\prime}, 7^{\prime}$-dichlorodihydrofluorescein diacetate (DCFH-DA) (Life Technologies) was used as a fluorogenic probe to evaluate intracellular ROS levels. Cells were seeded into 96-well culture plates $\left(3 \times 10^{3}\right.$ cells per well) and were treated with a series of concentrations of sauchinone $(0,5,10$, and $20 \mu \mathrm{M})$ for $2 \mathrm{~h}$, followed by incubation in HG (25 mM) condition for $48 \mathrm{~h}$. Subsequently, cells were treated with $10 \mathrm{mM}$ DCFH-DA for $15 \mathrm{~min}$ in the dark. Fluorescence intensity was determined using a Hitachi F-2000 fluorometer at excitation and emission wavelengths of $480 \mathrm{~nm}$ and $540 \mathrm{~nm}$, respectively (Hitachi, Tokyo, Japan).

\subsection{Measurement of antioxidant enzyme activities}

ARPE-19 cells treated with a series of concentrations of sauchinone $(0,5,10$, and $20 \mu \mathrm{M})$ for $2 \mathrm{~h}$, followed by incubation in HG ( $25 \mathrm{mM}$ ) condition for $48 \mathrm{~h}$. Then, ARPE-19 cells were harvested for the determination of antioxidant enzyme activities. The activities of superoxide dismutase (SOD), glutathione peroxidase (GPx), and catalase (CAT) were measured using corresponding commercial kits (Beyotime Biotechnology, Shanghai, China) following the manufacturer's instructions.

\subsection{Cell apoptosis assay}

For the cell apoptosis assay, the flow cytometry was performed with an annexin-V/propidium iodide (PI) Apoptosis Detection Kit (KeyGEN, Nanjing, China). In brief, ARPE-19 cells were pretreated with a series of concentrations of sauchinone $(0,5,10$, and 20 $\mu \mathrm{M})$ for $2 \mathrm{~h}$, followed by incubation in $\mathrm{HG}(25 \mathrm{mM})$ condition for 48 h. Subsequently, cells were collected and suspended in binding buffer. Fluorescein isothiocyanate (FITC)-conjugated annexin- $\mathrm{V}$ and PI were then added into the suspended cells and were incubated for $15 \mathrm{~min}$ at $37^{\circ} \mathrm{C}$ in the dark. Further, the double-stained cells were analyzed using a FACSCalibur flow cytometer (BD Biosciences, San Jose, CA, USA).

\subsection{Western blot analysis}

Cells were harvested and then lysed in RIPA buffer with protease inhibitors (Protease Inhibitor Cocktail, Sigma). For the detection of nuclear proteins, the nuclei of ARPE-19 cells were separated by the Nuclei Isolation Kit (Sigma). After the determination of protein concentration, $50 \mu \mathrm{g}$ protein extracts were resolved in $12 \%$ SDS-PAGE and transferred to a PVDF membrane. After blocking by $5 \%$ non-fat milk for $1 \mathrm{~h}$ at room temperature, membranes were blotted in primary antibodies overnight at $4{ }^{\circ} \mathrm{C}$, followed by the incubation with secondary antibodies conjugated with horseradish peroxidase (1: 3000 dilution; Abcam, Cambridge, MA, USA) for $1 \mathrm{~h}$ at $37{ }^{\circ} \mathrm{C}$. The primary antibodies employed for blotting were as follows: anti-
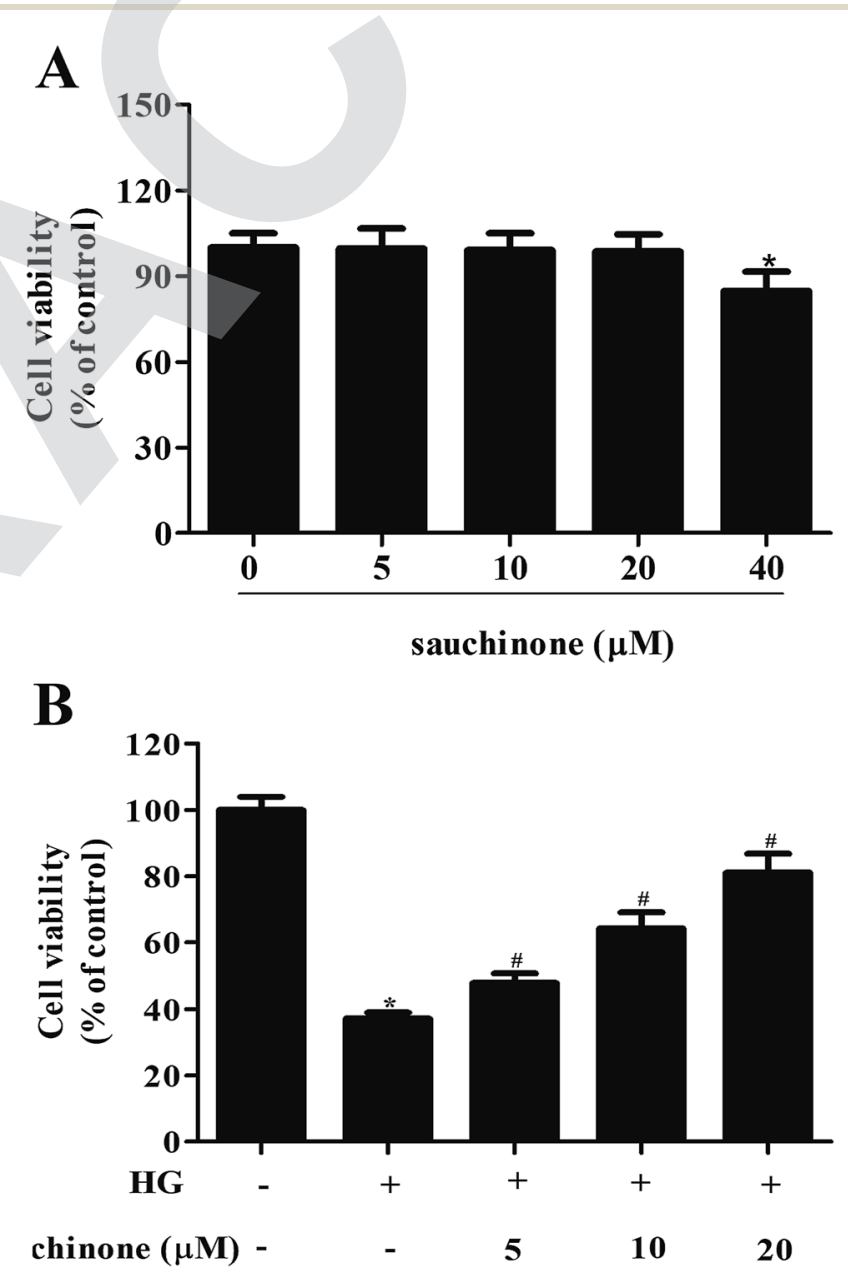

Fig. 1 Sauchinone improved cell viability of HG-induced ARPE-19 cells. (A) Effect of sauchinone on ARPE-19 cells viability. ARPE-19 cells were incubated with a series of concentrations of sauchinone $(0,5,10$, $20,40 \mu \mathrm{M}$ ) for $48 \mathrm{~h}$. (B) Effect of sauchinone on cell viability of HGinduced ARPE-19 cells. Cells were pretreated with different dosages of sauchinone $(0,5,10$ and $20 \mu \mathrm{M})$ for $2 \mathrm{~h}$, followed by incubation in $\mathrm{HG}$ $(25 \mathrm{mM})$ condition for $48 \mathrm{~h}$. All results were expressed as means $\pm \mathrm{SEM}$ of three independent replications. ${ }^{*} p<0.05$ vs. control cells; ${ }^{*} p<0.05$ vs. HG-induced ARPE-19 cells. 
bax (1: 1000 dilution; Invitrogen, Carlsbad, CA, USA), anti-bcl-2 (1: 500 dilution; Abcam), anti-p-Akt (1: 1000 dilution; Invitrogen), anti-Akt (1: 1000 dilution; Invitrogen), anti-nuclear factor erythroid 2-related factor (Nrf2; 1: 500 dilution; Abcam), anti-heme oxygenase-1 (HO-1; 1: 500 dilution; Abcam), and anti$\beta$-actin (1: 1000 dilution; Invitrogen). The signals were visualized using an ECL kit (Thermo Fisher Scientific) and Image J software (National Institutes of Health, NIH, Bethesda, MD, USA), respectively.

\subsection{Statistical analysis}

Quantitative data were presented as mean value \pm SEM. Statistical tests were performed with GraphPad Prism 5.0 (GraphPad Software, San Diego, CA, USA). Moreover, comparisons among multiple groups were made using One-Way ANOVA, followed by Bonferroni's multiple comparison tests. Statistical significance is shown as $* p<0.05$.

\section{Results}

\subsection{Sauchinone significantly increased cell viability in HG- induced RPE cells}

First, we evaluated the cytotoxicity effect of sauchinone on ARPE-19 cells by incubating with a series of concentrations of sauchinone $(0,5,10,20$, and $40 \mu \mathrm{M})$ for $48 \mathrm{~h}$. MTT assay showed that the administration of $40 \mu \mathrm{M}$ sauchinone had a significant effect on cell viability; however, the viability of ARPE-19 cells was unaffected by sauchinone at concentrations of 5,10 , and 20 $\mu \mathrm{M}$ (Fig. 1A). Therefore, $5-20 \mu \mathrm{M}$ of sauchinone was used in the following experiments. Then, we investigated the effect of sauchinone on the cell viability of HG-induced ARPE-19 cells. Fig. 1B shows that HG caused a significant decrease in the cell viability of ARPE-19 cells, while sauchinone treatment (5, 10, and $20 \mu \mathrm{M}$ ) attenuated the inhibitory effect of HG stimulation on the ARPE-19 cells viability.

\subsection{Sauchinone ameliorated HG-induced oxidative stress in RPE cells}

In order to explore the effect of sauchinone on oxidative stress in ARPE-19 cells, the ROS generation and the activities of antioxidant enzyme including SOD, GPx, and CAT were determined. As shown in Fig. 2A, ROS generation in ARPE-19 cells was markedly induced by HG stimulation, while the increased ROS generation was revered by sauchinone treatment $(5,10$, and 20 $\mu \mathrm{M})$. Moreover, HG stimulation caused a significant decrease in the activities of SOD, GPx, and CAT. However, the inhibition of SOD, GPx, and CAT activities in HG-induced ARPE-19 cells was

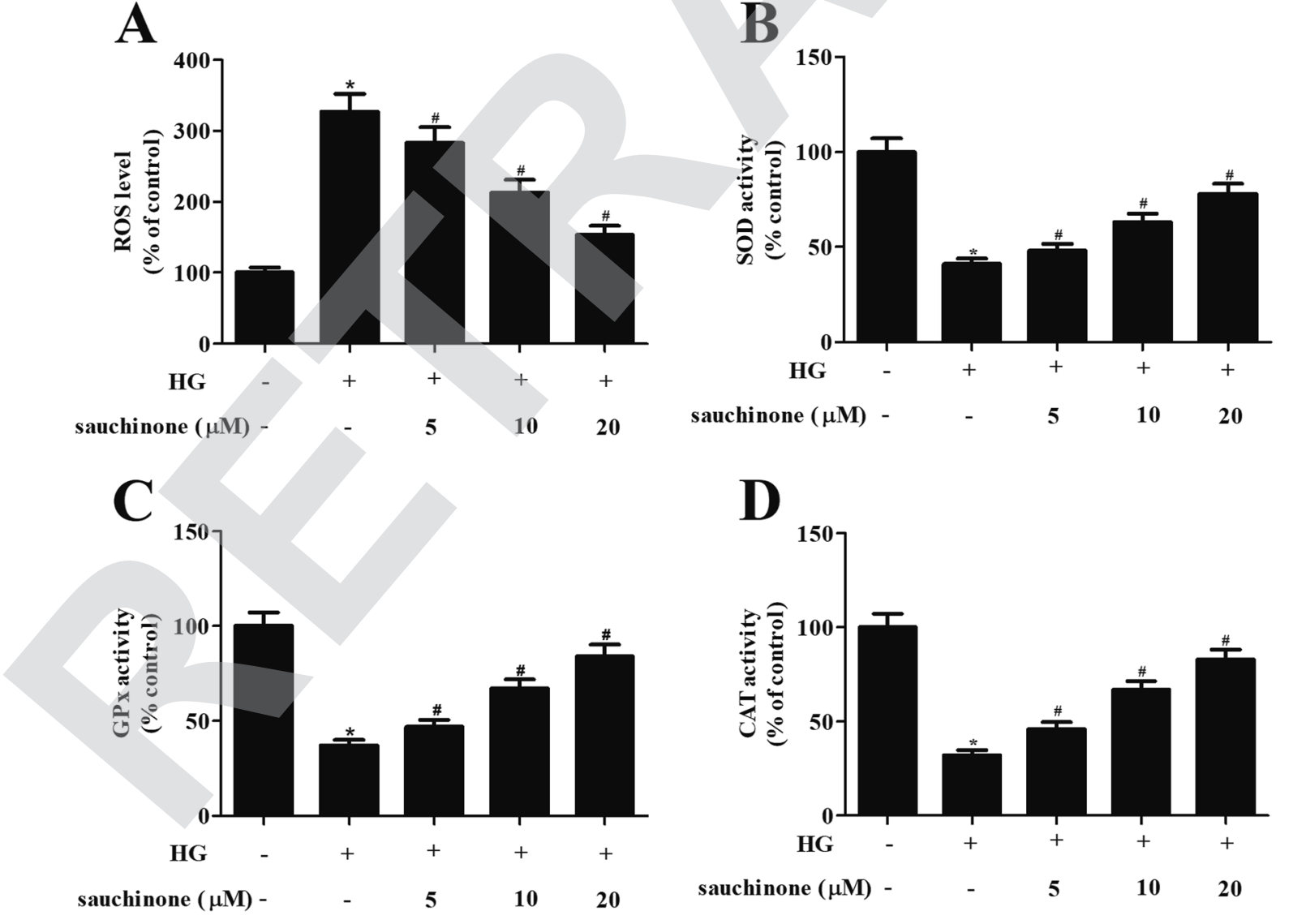

Fig. 2 Sauchinone ameliorated oxidative stress in HG-induced ARPE-19 cells. Cells were pretreated with a series of concentrations of sauchinone $(0,5,10,20 \mu \mathrm{M})$ for $2 \mathrm{~h}$, followed by incubation in HG $(25 \mathrm{mM})$ condition for $48 \mathrm{~h}$. ROS generation (A) and the activities of antioxidant enzyme activities including SOD (B), GPx (C), and CAT (D) were determined to reflect oxidative stress. All results were expressed as means \pm SEM of three independent replications. ${ }^{*} p<0.05$ vs. control cells; ${ }^{*} p<0.05$ vs. HG-induced ARPE-19 cells. 

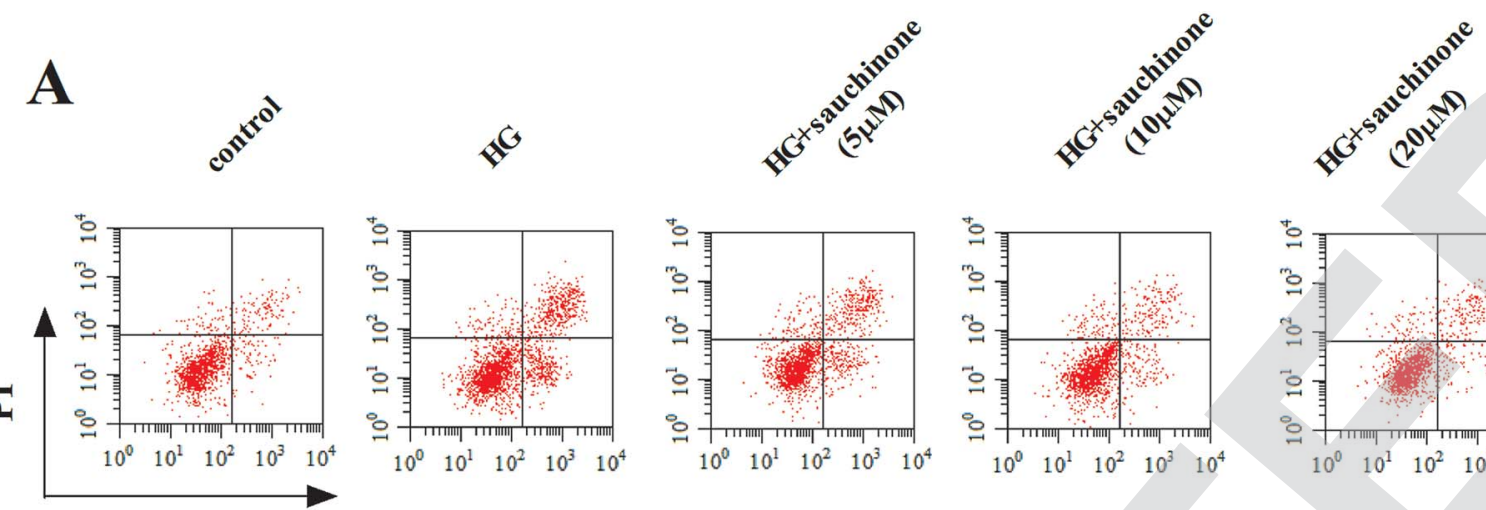

Annexin V-FITC
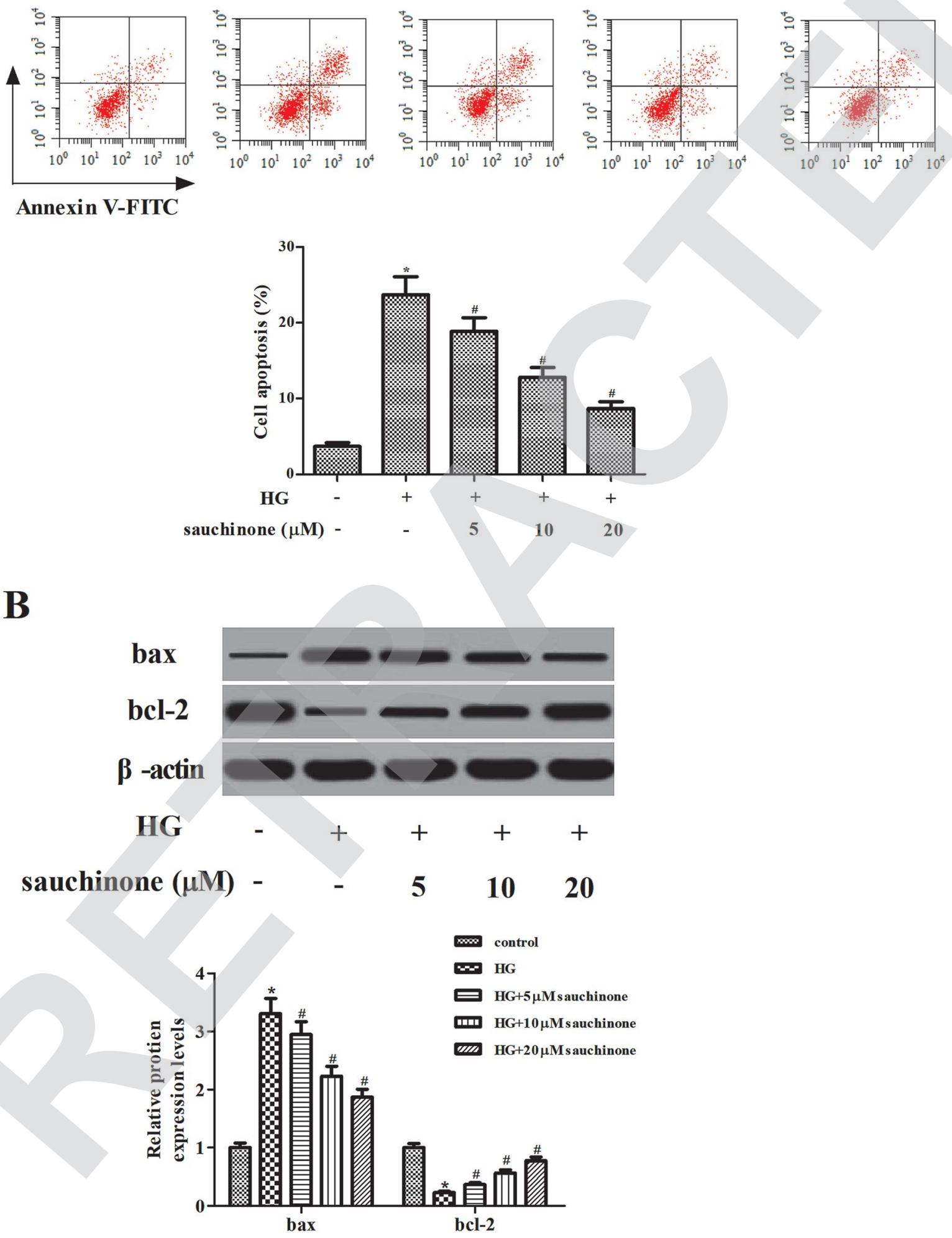

Fig. 3 Sauchinone ameliorated cell apoptosis in HG-induced ARPE-19 cells. After pretreatment with a series of concentrations of sauchinone (0, $5,10,20 \mu \mathrm{M})$ for $2 \mathrm{~h}$, ARPE-19 cells were incubated in $\mathrm{HG}(25 \mathrm{mM})$ condition for $48 \mathrm{~h}$. (A) Apoptotic rates of ARPE-19 cells were assessed using flow cytometry. (B) Expressions of bcl-2 and bax were detected using Western blot. All results were expressed as means \pm SEM of three independent replications. ${ }^{*} p<0.05$ vs. control cells; ${ }^{*} p<0.05$ vs. HG-induced ARPE-19 cells. 
A

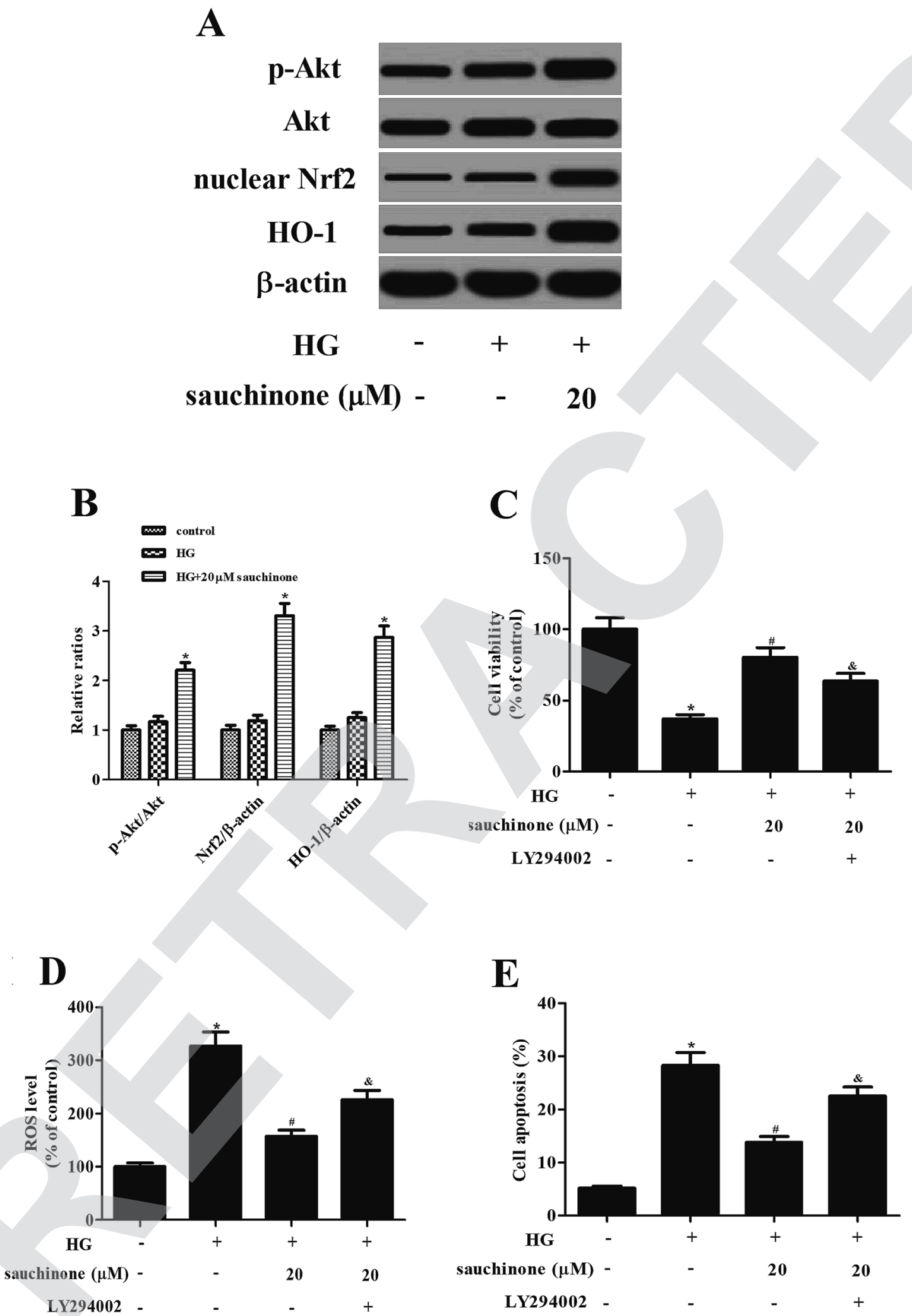

Fig. 4 Sauchinone enhanced the HG-induced activation of Akt/Nrf2/HO-1 signaling pathway in ARPE-19 cells. ARPE-19 cells were incubated with or without sauchinone $(20 \mu \mathrm{M})$ for $2 \mathrm{~h}$ in the presence or absence of HG (25 mM) condition. The expressions of Akt, p-Akt, nuclear Nrf2, and $\mathrm{HO}-1$ were assessed using Western blot analysis. (A) Effect of sauchinone on the activation of Akt/Nrf2/HO-1 signaling pathway. (B) Quantification analysis was performed using Gel-Pro Analyzer version 4.0 software. Cells were pretreated with $5 \mu$ M LY294002 for 1 h, and then incubated with or without sauchinone $(20 \mu \mathrm{M})$ for $2 \mathrm{~h}$ in the presence or absence of HG (25 mM) condition. (C) Effect of LY294002 on cell viability. (D) Effect of LY294002 on oxidative stress. (E) Effect of LY294002 on cell apoptosis. All results were expressed as means \pm SEM of three independent replications. ${ }^{*} p<0.05$ vs. control cells; ${ }^{*} p<0.05$ vs. HG-induced ARPE-19 cells; \&p $<0.05$ vs. HG + sauchinone group. 
mitigated by sauchinone treatment $(5,10$, and $20 \mu \mathrm{M})$ in a dosedependent manner (Fig. 2B-D).

\subsection{Sauchinone ameliorated HG-induced apoptosis in RPE cells}

Subsequently, the effect of sauchinone on apoptosis in ARPE-19 cells was assessed using flow cytometry. The results shown in Fig. 3A indicate that the apoptotic rate in HG-treated ARPE-19 cells was noticeably increased; however, sauchinone treatment $(5,10$, and $20 \mu \mathrm{M}$ ) significantly reduced the apoptotic rate. Besides, we measured the expressions of bcl-2 and bax using Western blot. As shown in Fig. 3B, HG stimulation caused a significant increase in the bax expression and decrease in the bcl-2 expression. The changes in the bax and bcl-2 expressions caused by HG stimulation were reversed by the sauchinone treatment $(5,10$, and $20 \mu \mathrm{M})$.

\subsection{Sauchinone induced the activation of the Akt/Nrf2/HO-1 signaling pathway in HG-treated RPE cells}

Akt/Nrf2/HO-1 signaling pathway was found to be involved in the HG-induced oxidative stress. ${ }^{12,13}$ To determine whether the Akt/Nrf2/HO-1 signaling pathway was implicated in the effects of sauchinone in HG-treated ARPE-19 cells, the expressions of Akt, p-Akt, nuclear Nrf2, and HO-1 were assessed. Western blot analysis proved that the HG stimulation slightly induced the expressions of p-Akt, nuclear Nrf2, and HO-1. Moreover, sauchinone treatment enhanced the HG-caused induction of p-Akt, nuclear Nrf2, and HO-1 expressions in ARPE-19 cells (Fig. 4A). However, the inhibitor of Akt, LY294002, reversed the protective effect of sauchinone on cell viability (Fig. 4C). The decrease in ROS generation caused by sauchinone was attenuated by LY294002 treatment (Fig. 4D). Thus, the sauchinone-induced inhibition of cell apoptosis was mitigated by LY294002 treatment (Fig. 4E).

\section{Discussion}

Diabetes is a major public health problem with the main hallmark of high circulating glucose. ${ }^{14}$ Chronic elevation in circulating blood glucose results in the blood vessels damage, which in turn leads to many kinds of micro and macrovascular complications. ${ }^{5}$ DR is one of the major microvascular complications, which affects the vision. HG-induced oxidative stress is an important contributor in the progress of DR. ${ }^{5}$ The production of ROS is up-regulated in diabetic conditions through the activation of many metabolic abnormalities, which are induced by HG. ${ }^{5}$ It has been demonstrated that retina is rich in polyunsaturated fatty acids with high levels of glucose oxygen uptake, making it a suitable target for oxidative damage. Excess ROS results in the damage of macromolecules and acts as cellular messengers to disrupt the normal mechanisms of cellular signaling, thereby causing cell injury and apoptosis in RPE cells. ${ }^{15}$ Moreover, the anti-oxidant defense mechanism gets compromised in diabetes, which impairs the scavenging of ROS and increases the oxidative burden. ${ }^{16}$ These results indicate that targeting oxidative stress and cell apoptosis is a potential therapeutic strategy in the prevention and treatment of DR.
Sauchinone has anti-oxidant and anti-apoptosis activities. For example, Kim et al. reported that sauchinone inhibited ironinduced oxidative stress, which depends on AMPK activation in mice. ${ }^{17}$ However, the role of sauchinone in DR remains unknown. Therefore, in the present study, we evaluated the effect of sauchinone on HG-induced RPE cells. The results showed that sauchinone treatment prevented HG-induced oxidative stress and apoptosis.

The multifunctional regulator Nrf2 is considered as a cytoprotective factor responsible for protecting cells from oxidative stress-induced cell injury. ${ }^{18,19}$ Under physiological conditions, Nrf2 binds to the inhibitor protein Kelch-like ECH-associated protein 1 (Keap1), which is responsible for the cytosolic sequestration of Nrf2, thereby promoting the ubiquitination and eventual degradation of Nrf2 ${ }^{18}$ Moreover, Nrf2 is released from Keap1 and translocates to the nucleus under the stressful conditions. ${ }^{18,20}$ The nuclear Nrf2 binds to the antioxidant response element (ARE) and regulates the transcription of genes coding for anti-oxidant, anti-inflammatory, and detoxifying proteins. ${ }^{20}$ Among these antioxidant enzymes, HO-1 is one of the target proteins that has beneficial effects such as the protection against oxidative injury, inflammation, and apoptosis. Overall, the Nrf2/ HO-1 signaling pathway plays a crucial role in the regulation of oxidative stress. ${ }^{21}$ The Akt pathway is a main intracellular signaling pathway that is involved in various cellular processes. ${ }^{22,23}$ Moreover, it has been found that the activation of the Akt pathway may trigger the Nrf2/HO-1 signaling pathway. ${ }^{24,25}$ Therefore, the elevation of the Akt/Nrf2/HO-1 signaling pathway is important for alleviating the oxidative damage.

Previous studies have proved that sauchinone inhibited IL-1 $\beta$ induced catabolism and hypertrophy in chondrocytes through activating the Nrf2/HO-1 signaling pathway. ${ }^{26}$ Sauchinone has also increased the cellular resistance of HepG2 cells to $t$-butyl hydroperoxide-induced oxidative injury through the Nrf2/AREdependent HO-1 pathway. ${ }^{27}$ Herein, we showed that sauchinone treatment enhanced the HG-caused induction of p-Akt, nuclear Nrf2, and HO-1 expressions in ARPE-19 cells. However, the inhibitor of Akt, Y294002, reversed the effects of sauchinone on cell viability, oxidative stress, and cell apoptosis. Thus, these findings suggested that sauchinone exerted its effects via regulating the Akt/Nrf2/HO-1 pathway in HG-induced RPE cells.

In summary, our results proved that sauchinone protected RPE cells from HG-induced oxidative stress and apoptosis. The protective effects were mediated by the activation of Akt/Nrf2/ HO-1 pathway. These findings suggested that sauchinone could have a therapeutic meaning in the treatment and prevention of DR.

\section{Conflicts of interest}

The authors declare that there are no conflicts of interest.

\section{References}

1 Y. Zheng, M. He and N. Congdon, The worldwide epidemic of diabetic retinopathy, Indian J. Ophthalmol., 2012, 60, 428-431. 
2 A. J. Jenkins, M. V. Joglekar, A. A. Hardikar, A. C. Keech, D. N. O'Neal and A. S. Januszewski, Biomarkers in Diabetic Retinopathy, Rev. Diabet. Stud., 2015, 12, 159-195.

3 K. M. West, L. J. Erdreich and J. A. Stober, A detailed study of risk factors for retinopathy and nephropathy in diabetes, Diabetes, 1980, 29, 501-508.

4 Y. Wu, L. Tang and B. Chen, Oxidative stress: implications for the development of diabetic retinopathy and antioxidant therapeutic perspectives, Oxid. Med. Cell. Longevity, 2014, 2014, 752387-752399.

5 R. A. Kowluru, A. Kowluru, M. Mishra and B. Kumar, Oxidative stress and epigenetic modifications in the pathogenesis of diabetic retinopathy, Prog. Retinal Eye Res., 2015, 48, 40-61.

6 F. Willermain, L. Scifo, C. Weber, L. Caspers, J. Perret and C. Delporte, Potential Interplay between Hyperosmolarity and Inflammation on Retinal Pigmented Epithelium in Pathogenesis of Diabetic Retinopathy, Int. J. Mol. Sci., 2018, 19, E1056, DOI: 10.3390/ijms19041056.

7 I. Y. Choi, Y. Hua, Y. K. Park and W. K. Kim, Sauchinone reduces oxygen-glucose deprivation-evoked neuronal cell death via suppression of intracellular radical production, Arch. Pharmacal Res., 2009, 32, 1599-1606.

8 B. Li, J. L. Yun, Y. C. Kim, J. J. Yoon, S. M. Lee, P. L. Yong, D. G. Kang and H. S. Lee, Sauchinone from Saururus chinensis protects vascular inflammation by heme oxygenase-1 induction in human umbilical vein endothelial cells, Phytomedicine, 2014, 21, 101-108.

9 Y. W. Kim, E. J. Jang, C. H. Kim and J. H. Lee, Sauchinone exerts anticancer effects by targeting AMPK signaling in hepatocellular carcinoma cells, Chem.-Biol. Interact., 2016, 261, 108-117.

10 Y. W. Kim and Y. Y. Kim, Inhibition of SREBP-1c-mediated hepatic steatosis and oxidative stress by sauchinone, an AMPK-activating lignan in Saururus chinensis, Free Radical Biol. Med., 2010, 48, 567-578.

11 J. Min-Ho, S. Min-Cheol, B. Kiho, K. H. Sung, K. Seung Hyun, S. S. Hyun, Y. S. Kyu, L. Kwang Ho, Y. Yeo-Pyo and K. TackJoong, Sauchinone attenuates oxidative stress-induced skeletal muscle myoblast damage through the downregulation of ceramide, Biol. Pharm. Bull., 2011, 34, 575-579.

12 B. Zhang, Y. Chen, Q. Shen, G. Liu, J. Ye, G. Sun and X. Sun, Myricitrin Attenuates High Glucose-Induced Apoptosis through Activating Akt-Nrf2 Signaling in H9c2 Cardiomyocytes, Molecules, 2016, 21, E880, DOI: 10.3390/ molecules21070880.

13 L. Liu, W. Huang, J. Wang, H. Song, J. Cen and B. Ji, Anthraquinone derivative exerted hormetic effect on the apoptosis in oxygen-glucose deprivation-induced PC12 cells via ERK and Akt activated Nrf2/HO-1 signaling pathway, Chem.-Biol. Interact., 2017, 262, 1-11.
14 R. H. Unger, Reinventing type 2 diabetes: pathogenesis, treatment, and prevention, J. Am. Med. Assoc., 2008, 299, 1185-1187.

15 R. G. Cutler, Oxidative stress profiling: part I. Its potential importance in the optimization of human health, Ann. N. Y. Acad. Sci., 2005, 1055, 93-135.

16 R. A. Kowluru, T. S. Kern and R. L. Engerman, Abnormalities of retinal metabolism in diabetes or experimental galactosemia. IV. Antioxidant defense system, Free Radical Biol. Med., 1997, 22, 587-592.

17 Y. W. Kim, S. M. Lee, S. M. Shin, S. J. Hwang, J. S. Brooks, H. E. Kang, M. G. Lee, S. C. Kim and S. G. Kim, Efficacy of sauchinone as a novel AMPK-activating lignan for preventing iron-induced oxidative stress and liver injury, Free Radical Biol. Med., 2009, 47, 1082-1092.

18 L. Baird and A. T. Dinkova-Kostova, The cytoprotective role of the Keap1-Nrf2 pathway, Arch. Toxicol., 2011, 85, 241-272.

19 M. Kobayashi and M. Yamamoto, Nrf2-Keap1 regulation of cellular defense mechanisms against electrophiles and reactive oxygen species, Adv. Enzyme Regul., 2006, 46, 113140.

20 T. W. Kensler, N. Wakabayashi and S. Biswal, Cell survival responses to environmental stresses via the Keap1-Nrf2ARE pathway, Annu. Rev. Pharmacol. Toxicol., 2007, 47, 89116.

21 A. Loboda, M. Damulewicz, E. Pyza, A. Jozkowicz and J. Dulak, Role of Nrf2/HO-1 system in development, oxidative stress response and diseases: an evolutionarily conserved mechanism, Cell. Mol. Life Sci., 2016, 73, 32213247.

22 D. R. Simpson, L. K. Mell and E. E. Cohen, Targeting the $\mathrm{PI} 3 \mathrm{~K} / \mathrm{AKT} / \mathrm{mTOR}$ pathway in squamous cell carcinoma of the head and neck, Oral Oncol., 2015, 51, 291-298.

23 V. Dimitrova and A. Arcaro, Targeting the PI3K/AKT/mTOR signaling pathway in medulloblastoma, Curr. Mol. Med., 2015, 15, 82-93.

24 X. Qin, C. Qiu and L. Zhao, Maslinic acid protects vascular smooth muscle cells from oxidative stress through Akt/ Nrf2/HO-1 pathway, Mol. Cell. Biochem., 2014, 390, 61-67.

25 J. Li, Y. Zhang, H. Luan, X. Chen, Y. Han and C. Wang, lcarnitine protects human hepatocytes from oxidative stress-induced toxicity through Akt-mediated activation of Nrf2 signaling pathway, Can. J. Physiol. Pharmacol., 2016, 94, 517-525.

26 D. Wu, S. Jin, Z. Lin, R. Chen, T. Pan, X. Kang, H. Huang, C. Lin and J. Pan, Sauchinone inhibits IL-1 $\beta$ induced catabolism and hypertrophy in mouse chondrocytes to attenuate osteoarthritis via Nrf2/HO-1 and $\mathrm{NF}-\kappa \mathrm{B}$ pathways, Int. Immunopharmacol., 2018, 62, 181-190.

27 G. S. Jeong, D. S. Lee, B. Li, E. Byun, D. Y. Kwon, H. Park and Y. C. Kim, Protective effect of sauchinone by upregulating hemo oxygenase-1 via the p38 MAPK and Nrf2/ARE pathways in HepG2 cells, Planta Med., 2010, 76, 41-47. 